\title{
Study of Cognitive Evoked Potentials in Type 2 Diabetes Mellitus
}

\author{
Sindhuja.A ${ }^{1}$, R.Ramya ${ }^{2}$ \\ ${ }^{1}$ Assistant Professor, Department of Physiology, The Oxford Medical College Hospital and Research centre, \\ Yadavanahalli, Attibele, Bangalore. Karnataka, ${ }^{2}$ Assistant Professor, Department of Physiology, Apollo Institute of \\ Medical Sciences and Research, Murakambattu, Chittoor, Andhra Pradesh
}

\begin{abstract}
Background: The completesyndrome of diabetes mellitus,related metabolic aberrations anddiabetic complications is posing a major threat in the $21^{\text {st }}$ century. Cognitive dysfunction is a well known complication of diabetes which continues to be investigated.

Aims and Objectives: To evaluate the cognitive functions using electrophysiological $\left(\mathrm{P}_{300}\right.$ latencies $)$ tests in diabetics and non diabetics in the age group of 40 - 59 years with same gender proportion, to analyze whether cognition is affected in diabetics when compared to non diabetics and to know the usefulness of electrophysiological ( $\mathrm{P}_{300}$ latencies) tests in detecting subtle cognitive changes.

Materials and Method: The study was conducted on 50 diabetics and 50 non diabetics aged between 40 and 59 years. Cognition was assessed using $\mathrm{P}_{300}$ potential.The evoked potential data analysis was done using Student unpaired $\mathrm{T}$ test to compare the mean of two groups.

Results: The absolute peak latencies of $\mathrm{P}_{3}$ component of endogenous cognitive evoked potentials was significantly prolonged among diabetics $(334.8 \pm 20.8)$ as compared to controls $(285.7 \pm 14.9)$. There was no statistically significant difference between groups when analyzed for $\mathrm{N}_{2}$ in $\mathrm{C}_{\mathrm{z}}$ and $\mathrm{F}_{\mathrm{z}}$.

Conclusion: This study identifies prevalence of cognitive dysfunction in diabetic patients when assessed using electrophysiological tests.Good cognitive function is critical to safely manage diabetesand draws attention to various challenges in their management. Clinicians should consider screening for cognitive function in diabetics using $\mathrm{P}_{300}$, as it is effective in detecting subtle changes much before their clinical manifestation.
\end{abstract}

Key words: Diabetes Mellitus; Cognition; Cognitive evoked potential; Event related potentials; NIDDM; $P_{300^{\circ}}$

\section{Introduction}

Diabetes mellitus (DM) is taking its place as a main threat to human health in the $21^{\text {st }}$ century. Type 2 DMis a complex metabolic disorder that results from

\footnotetext{
Corresponding Author:

Dr. R.Ramya,

Assistant Professor, Department of Physiology, Apollo Institute of Medical Sciences and Research, Murakambattu, Chittoor, Andhra Pradesh. PIN- 517 127. Email: ramyamayudhar@gmail.com, Ph. No. : 9562452446
}

an interaction between genetic predisposition and environmental factors. It accounts for about $90 \%$ of all cases of diabetes. ${ }^{1}$ The prevalence of DM is rapidly increasing as a result of longevity, urbanization, traditional family structure, mechanized work and associated lifestyle changes. ${ }^{2}$

The number of people with DM worldwide has increased more than two fold over the past three decades. In 2011, approximately 366 million people worldwide had DM, $90 \%$ of whom had type 2 DM. The number of people globally with DM is estimated to be 552 million ( 87 million in India) by 2030 , which will represent 
$7.8 \%$ of the total adult population of the world in the age group of 20-79 years. The major burden of DM is in developing countries. $80 \%$ cases of DM live in less developed countries. ${ }^{3} \mathrm{DM}$ is known to have devastating complications on multiple organs in the body. The chronic course of DM is associated with renal, retinal, cardiovascular, nervous system complications like brain hemorrhage, ischemia, peripheral and autonomic neuropathy. ${ }^{4}$ Higher brain activities like message comprehension and mnemonic capacities have not been monitored in diabetics due to non availability of biological markers. ${ }^{5}$

A well recognized nervous system complication of elderly diabetics which is less addressed is cognitive dysfunction. ${ }^{6}$

Cognitive impairment in diabetes in terms of speed of processing, memory and attention was observed in patients with DM especially during hyperglycemia. ${ }^{7}$

Cognitive $\mathrm{P}_{300}$ potential has been used as a noninvasive, objective and quantitative method to assess higher cognitive functions of human brain. These potentials express the aptitude of human brain to discriminate, classify, decide and memorize the significance of an exogenous stimulus.It serves as a tool to check the sequelae caused by hypoglycemia in hippocampus region, which is evident even before there is clinical manifestation of nervous system damage. ${ }^{8,9}$

Concomitant cognitive dysfunction in diabetic patients generally goes unnoticed. Cognitive dysfunction is an important co morbidity that needs to be addressed in diabetic population. This aroused the need for screening subtle cognitive dysfunction in diabetics which are often unrecognizable.

Recognizing these asymptomatic cerebral changes and modifiable risk factors that influence cognitive changes in diabetes can put forward preventive treatment of the condition and thereby improve the quality of life so as to - "Achieve tightest possible glycemic control with lowest possible chances of hypoglycemia".

\section{Materials and Method}

The present study was conducted in the auspices of research laboratory of Department of Physiology, S.S.Institute of Medical Sciences \& Research Centre, Davangere. Study design was of case control type.

\section{Selection of participants:}

- $\quad$ The study comprised of 100 randomly selected subjects in the age group of $40-59$ years.

- $\quad$ The case group comprised of 28 diabetic males and 22 diabetic females.

- The control group included 30 non diabetic males and 20 non diabetics females in the same age group.

\section{Inclusion criteria:}

\section{* Cases:}

- Known diabetic between 40 and 59 years of age.

- Newly diagnosed cases between 40 and 59 years of age.

\section{* Controls:}

- Non diabetics between 40 and 59 years of age in same gender proportion.

- Same socioeconomic and educational background as diabetics.

\section{Exclusion criteria}

- Hearing loss.

- Old age (above 60years)-Dementia, Alzheimer's disease.

- Stroke.

- Recurrent hypoglycemic episodes.

- Parkinson's disease.

- HIV dementia complex.

- Psychiatric disorders like Schizophrenia and depression.

- Nutritional deficiency - Vitamin $\mathrm{B}_{12}$.

- Hepatic encephalopathy.

- Alcoholism.

After obtaining Institutional ethics committee approval and written informed consent, the patient's blood glucose levels were estimated to check their glycemic status on the day of cognitive assessment 
Electrophysiological test was recorded using RMS EMG EP MARK II supplied by recorders and medicare system (P) limited, Chandigarh.

\section{Data Analysis}

Data analysis was done using SPSS software. Student unpaired $\mathrm{T}$ test to compare the mean of evoked potentials between the two groups.Differences were considered significant at $\mathrm{P}<0.001$.

\section{Results}

The study was conducted among diabetics and non diabetics to find out relationship between diabetes and cognition, in the age group of 40-59 years. The data was analyzed by using SPSS 18 and excel was used to generate graphs, tables etc.

Analysis was done using appropriate statistical tests to compare mean values of different parameters between 2 groups.P value was significant at $\leq 0.001$. Mean and standard deviation were calculated for baseline characteristics and electrophysiological test. Cases and controls were compared using Student's unpaired $\mathrm{T}$ test. Table 1 shows the comparison between the baseline characteristics of subjects. Table 2 shows the Comparison of cognitive evoked potential in study group and control group. It shows that the absolute peak latencies of $\mathrm{P}_{300}$ component of endogenous cognitive evoked potentials was significantly prolonged among diabetics as compared to controls. Graph 1 illustrates that Amplitude of $\mathrm{P}_{300}-\mathrm{N}_{2}$ is higher in cases than that of controls.

Table 1: Baseline physical characteristics.

\begin{tabular}{|l|l|l|l|}
\hline Parameter & Case & Control & $\begin{array}{l}\text { P* } \\
\text { Value }\end{array}$ \\
\hline Age (Years) & $52.7+7.1$ & $50.06+6.3$ & 0.052 \\
\hline Pulse (bpm) & $73.8+7.1$ & $74.72+6.1$ & 0.46 \\
\hline SBP (mmHg) & $127.6+13.0$ & $126+7.6$ & 0.45 \\
\hline DBP (mmHg) & $77.8+6.2$ & $79.2+4.0$ & 0.17 \\
\hline BMI (Kg/m2) & $25.3+3.5$ & $23.9+3.1$ & 0.03 \\
\hline$*$ Student's unpaired t test, & \\
\hline
\end{tabular}

I. Comparison of cognitive evoked potential in study group and control group.
Table 2. Cognitive evoked potential.

\begin{tabular}{|l|l|l|l|}
\hline Parameter & Cases & Controls & P* Value \\
\hline $\begin{array}{l}\text { N100 latency } \\
(\mathrm{ms})\end{array}$ & $76.0+20.9$ & $77.4+19.5$ & 0.73 \\
\hline $\begin{array}{l}\text { P200 } \\
\text { latency }(\mathrm{ms})\end{array}$ & $\begin{array}{l}167.3+ \\
26.3\end{array}$ & $\begin{array}{l}165.4+ \\
29.3\end{array}$ & 0.73 \\
\hline $\begin{array}{l}\text { N200 } \\
\text { latency }(\mathrm{ms})\end{array}$ & $\begin{array}{l}185.0+ \\
31.2\end{array}$ & $179.7+29$ & 0.30 \\
\hline $\begin{array}{l}\text { P300 } \\
\text { latency(ms) }\end{array}$ & $\begin{array}{l}334.8+ \\
20.8\end{array}$ & $\begin{array}{l}285.7+ \\
14.9\end{array}$ & $<0.001 *$ \\
\hline P300-N2( $\mu \mathrm{V})$ & $6.0+3.8$ & $5.8+4.7$ & 0.79 \\
\hline $\begin{array}{l}* \text { Student's unpaired t test, } \\
\text { P }<0.001\end{array}$ & & \\
\hline
\end{tabular}

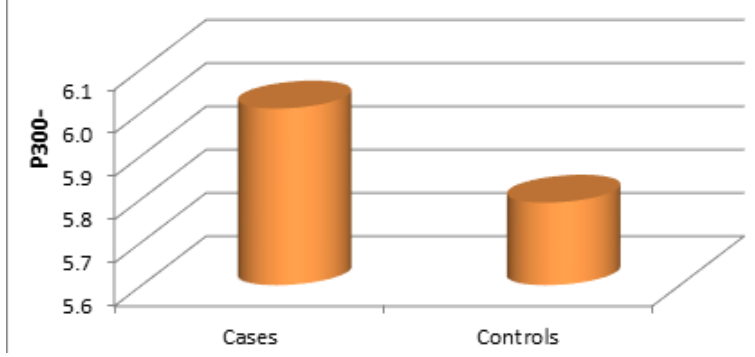

Graph 1: Amplitude of $P_{300}-N_{2}$ among cases and controls.

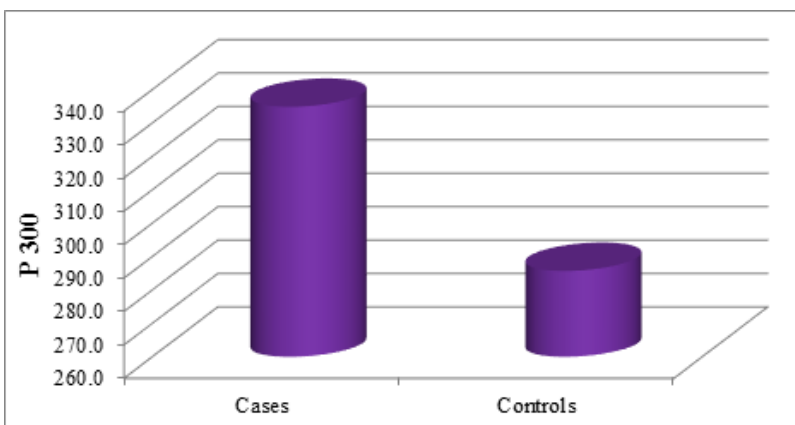

Graph 2: Latency of $\mathbf{P}_{300}$ among cases and controls.

Mean $\mathrm{P}_{300}$ latency for case group was $334.8+20.8 \mathrm{~ms}$ and that of controls was $285.7+14.9 \mathrm{~ms}$. The difference was highly significant with a $\mathrm{P}$ value of $<0.001$. There was no significant difference in amplitude of $\mathrm{P}_{300}-\mathrm{N}_{2}$, latencies of $\mathrm{N}_{2}$ and $\mathrm{P}_{2}$.

\section{Discussion}

The diabetic patients complain of loss of memory and poor ability to concentrate. Self management of diabetes including avoidance of hypoglycemia is complex. The cerebral mechanism underlying the cognitive deficits and the responsible brain structures remains to be delineated. They are the topics of intense research, but brain atrophy and vascular changes have 
both been assumed. ${ }^{10}$

In previous studies, $\mathrm{P}_{300}$ latencies in diabetics were either prolonged or tend to be prolonged in $\mathrm{C}_{\mathrm{z}}$ and $\mathrm{F}_{\mathrm{z}}$ compared to controls. ${ }^{11,12}$ In a study $\mathrm{P}_{300}$ latency was not elevated significantly at all sites but longer latency was observed at $\mathrm{F}_{\mathrm{z}}$ and $\mathrm{C}_{\mathrm{z}}{ }^{13}$

Concerning the amplitude of $\mathrm{P}_{300}$ the data are sparse. Most authors did not report measurement of amplitude ${ }^{14}$, 12 In others, there was no statistically significant difference between patients and control. ${ }^{15}$

In our study absolute peak latencies of $\mathrm{P}_{300}$ component of endogenous cognitive evoked potentials was significantly prolonged among diabetics as compared to controls. The amplitude did not differ significantly in the two groups.

The $\mathrm{N}_{100}$ and $\mathrm{P}_{200}$ components are believed to reflect the activity in neural areas that are activated by sensory modality and are independent of the attention of the subject. ${ }^{16}$ The $\mathrm{N}_{200}$ component is related to the unexpectedness of the stimulus. It is regarded as a measure of the time of early stimulus processing, engaging orientation and attention. $\mathrm{P}_{300}$ latency is regarded as a measure of stimulus classification, speed, reflection of memory and storage that are initiated in the hippocampus which is considered to be $\mathrm{P}_{300}$ generator. The $\mathrm{P}_{300}$ amplitude represents online updating of working memory and / or attention process involved in working memory. ${ }^{17,18}$

Since the latencies of $\mathrm{N}_{100}, \mathrm{~N}_{200}$ and $\mathrm{P}_{200}$ did not differ between cases and controls, prolongation of $\mathrm{P}_{300}$ latenciescannot be attributed to delay in perceptual encoding. It is thought to be produced by interaction between frontal lobe, hippocampus, temporal and parietal process. Hippocampus is involved in learning and memory. The delayed $\mathrm{P}_{3}$ in NIDDM therefore reflects inhibition or possible damage of this area. ${ }^{14}$ Diabetic milieu causes delay in cognitive processes by interacting with $\mathrm{N}_{200}$ and $\mathrm{P}_{3}$ generators in cerebral cortex. ${ }^{17}$

The observed electrophysiological abnormality reflects impairment in attention, memory and speed of information processing which is indicative of early cognitive impairment in diabetes.

Medical care alone in the absence of adequate self-care is rarely effective for chronic illnesses like Diabetes. Self care in diabetes has important clinical and public health implications ${ }^{19}$ Since the incidence of Alzheimer's disease is increasing in diabetics, assessing cognitive function is very essential in preventing this co morbidity in the elderly diabetics. ${ }^{6}$ Older women with diabetes have poorer cognitive functioning and a more rapid cognitive decline than women with normal blood glucose level. ${ }^{20}$ Studies show that improving the metabolic control in IDDM patients with vigorous and continuous insulin, further deteriorates their cognition. ${ }^{21}$

\section{Limitations of the Study}

- The present study is a case control study where subjects were randomly selected from population. A large population based study is required to extrapolate these findings to general population.

- The study does not correlate glycemic status and duration of diabetes mellitus with that of cognitive function, which would establish a better association of cognitive function and glycemic status.

\section{Conclusion}

The aim of this study was to assess cognitive function in type $2 \mathrm{DM}$ and to find out the usefulness of electrophysiological tests in detecting cognitive changes.

In general we found that there was statistically significant difference in $\mathrm{P}_{300}$ latency between diabetics and non diabetics, with higher latency in diabetic group when compared to non diabetic group. The amplitude did not differ among the two groups. These results prove that diabetes affects cognition. The cognitive impairment was evident with electrophysiological tests. This highlights the fact that electrophysiological tests are highly sensitive in detecting early cognitive impairment in diabetic patients.

Conflicts of Interest: None

Source of Funding: No Funding

Ethical Clearance: Institutional ethics committee clearance was obtained before the start of the study.

\section{References}

1. Fauci AS, Braunwald E, Kasper DL, Hauser SL, Longo DL, Jameson JL, et al. Harrison's principles of internal medicine. $17^{\text {th }}$ ed. McGraw-Hill; 2008. $2275-2304$.

2. Zimmet P. Alberti K G \& Shaw J. Global and societal implications of the diabetes epidemic. 
Nature 2001; 414: 782 - 789.

3. IDF Diabetes atlas, 5th edition. International Diabetes Federation 2012.

4. The Diabetes Control and ComplicationsTrial Research Group: The effect of intensivetreatment of diabetes on the developmentand progression of long-term complications in insulin-dependent diabetes mellitus. N Engl J Med 1993; 329: 977986.

5. Worral G, Moulton N, Briffett E. Effect of type II diabetes mellitus on cognitive function. J Fam Pract1993; 36: 639-643.

6. Arvanitakis Z, Wilson RS, Bienias JL,Evans DA, Bennet DA. Diabetes mellitus and risk of Alzheimer disease and decline in cognitive function. Arch Neurol 2004; 61: 661 - 666.

7. Sommerfield AJ, Deary IJ, Frier BM. Acute hyperglycemia alters mood state and impairs cognitive performance in people with type 2 diabetes. Diabetes care. 2004; 27 (10): 2335-2340.

8. Donchin E, Ritter W, Mccallum WC. Cognitive psychophysiology: The endogenous components of the ERP. InEvent-Related Brain Potentials of Event related Brain Potentials in Man. Academic Press, New York 1978; 349-411.

9. Di Leo MA, Di Nardo W, Cercones S, Ciervo A, Lo Monaco M, Greco AV, et al. Cochlear dysfunction in IDDM patients with subclinical peripheral neuropathy. Diabetes Care 1997; 20 (11): 18001803.

10. Biessels GJ, Koffeman A, Scheltens P. Diabetes and cognitive impairment, Clinical diagnosis and brain imaging in patients attending a memory clinic. J Neurol 2006; 253: 477-482.

11. Hissa MN, Artur CJ, D’Almeida, Cremasco F, Bruin VMS. Event related potential in NIDDM patients without cognitive impairment and its relationship with previous hypoglycemic episodes. Neuroendocrinollet 2002; 23: 226-230.

12. Pozzessere G, Valle E, Crignis S D, Cordischi VM, Fattapposta F, Rizzo PA et al. Abnormalities of cognitive function in insulin dependent diabetes mellitus revealed by P300 event related potential analysis compared with short latency evoked potentials and psychometric tests. Diabetes1991; 40(8): 952-958.

13. Mooradian AD, Perryman K, Fitten J, Kavonian GD and Morley JE . Cortical function in elderly noninsulin dependent diabetes patients. Arch Intern Med 1988; 1489(11): 2369-2372.

14. Tandon OMP, Verma A and Ram BK. Cognitive dysfunction in NIDDM: p3 event related evoked potential study. Indian J PhysiolPharmacol 1999; 43 (3): 383-388.

15. Andreadou E, Mitrakou A, Constantindes VC, Triantafyllou N. Auditory P300 event related potentials in patients with type 2 diabetes mellitus. J Diab Res Clin Met 2012; 1-7.

16. Picton, TW and Hillyard SA. Human auditory evoked potentials. II. Effects of attention. Electroencephalogr Clin Neurophysiol 1974; 36: 191-199.

17. Ritter W, Ford JM, Gaillard AWK, Harter RM, Renault DMK, Rohrbaugh J Cognition and eventrelated potentials. I. The relation of negative potentials and cognitive processes. Ann N Y Acad Sci 1984; 425:24-38

18. Polich, J. Attention, probability, and task demands as determinants of P300 latency from auditory stimuli. Electroencephalogr Clin Neurophysiol 1986; 63: 251-259.

19. Korff VM, Gruman J, Schaefer J, Curry SJ, Wagner EH: Collaborative management of chronic illness. Ann Intern Med 1997; 127: 1097 -1102.

20. Gregg EW, Yaffe K, Cauley JA, Rolka DB, Blackwell TL, Narayan KMV et al. Is diabetes associated with cognitive impairment and cognitive decline among older women? Arch Intern Med 2000; 160: $174-180$.

21. Connis RT, Taylor TR, Gordon MJ, Mecklenburg RS, Li ljenguist JE, Stephens JW, Baker MS. Changes in cognitive and social functioning ofdiabetic patients following initiation of insulin infusion therapy. Exp Aging Res 1989; 15: 51-60. 